\title{
Impact of atopic dermatitis on the quality of life of Nigerian children: A hospital-based cross-sectional study
}

\author{
O T Puddicombe, ${ }^{1} \mathrm{MBBS}$, FWACP; O A Odusote, ${ }^{2} \mathrm{MB}$ ChB, FMCPaed, MPhil; F E A Lesi, ${ }^{3} \mathrm{MBBS}, \mathrm{FWACP}, \mathrm{MSc}, \mathrm{FRCP}$ \\ A O Ayanlowo, ${ }^{4} \mathrm{MBBS}, \mathrm{FWACP}, \mathrm{MSc}$ \\ ${ }^{1}$ Dermatology Unit, Department of Paediatrics, Massey Street Children's Hospital, Lagos, Nigeria \\ ${ }^{2}$ Allergy, Dermatology and Pulmonary Medicine Unit, Department of Paediatrics, Lagos State University Teaching Hospital, Nigeria \\ ${ }^{3}$ Department of Paediatrics, Lagos University Teaching Hospital, Nigeria \\ ${ }^{4}$ Dermatology Unit, Department of Internal Medicine, Lagos University Teaching Hospital, Nigeria
}

Corresponding author: O T Puddicombe (seunpuddicombe@gmail.com)

\begin{abstract}
Background. Atopic dermatitis (AD) is the most common inflammatory skin disease in childhood. A skin disorder with a relapsing course, $\mathrm{AD}$ exerts a significant disease burden on affected children. However, there is a dearth of knowledge about the impact of AD on the quality of life (QOL) of affected children in Nigeria.

Objectives. To examine the impact of $\mathrm{AD}$ on QOL in children of various age groups, and to identify the relationship between patient variables (age, gender, socioeconomic status), disease severity and QOL in AD.

Method. This was a cross-sectional descriptive study of children with AD attending the dermatology clinic of Lagos University Teaching Hospital, Idi-Araba, Lagos, Nigeria. AD cases were recruited from new paediatric patients $\leq 16$ years who attended the clinic over a 6-month period. English and Yoruba versions of the Infants' Dermatitis Quality of Life Index (IDQOL) and the Children's Dermatology Life Quality Index (CDLQI) were used to determine the QOL of the subjects. AD severity was evaluated using the Objective SCORing of Atopic Dermatitis (obj-SCORAD) index.

Results. Forty-seven subjects with AD were identified. Their ages ranged from newborn to 16 years. The median(interquartile range (IQR)) IDQOL score was 6.0 (3.0 - 15.5; $n=25)$, and the median (IQR) CDLQI score was $9.5(7.75-17.75 ; n=22)$. The mean (standard deviation) obj-SCORAD score was 34.4 (17.2). The question on itching was the highest-scoring question in both QOL questionnaires. There was no significant difference in QOL across age, gender and socioeconomic status groups. However, greater QOL scores were significantly correlated with higher $\mathrm{AD}$ severity scores.

Conclusion. The study confirms that AD impairs the QOL of affected children in all age groups. QOL assessments are relevant tools which provide a patient's perspective, thus improving the understanding of the impact of $\mathrm{AD}$ on afflicted individuals.

S Afr J Child Health 2018;12(4):137-142. DOI:10.7196/SAJCH.2018.v12i4.1449
\end{abstract}

Atopic dermatitis (AD) is the most common inflammatory skin condition observed in children. ${ }^{[1]}$ This disease follows a chronic relapsing course, and may be associated with respiratory allergies such as asthma or allergic rhinitis (the atopic triad). ${ }^{[2]}$ The prevalence of $\mathrm{AD}$ shows worldwide variation between $2 \%$ and $20 \% .{ }^{[1]}$ In Nigeria, prevalence rates range from $4.2 \%$ to $15.5 \%$, with lower prevalence rates reported among children in rural areas and of lower socioeconomic class. ${ }^{[3-5]} \mathrm{AD}$ occurs most commonly among infants, and prevalence decreases with increasing age. ${ }^{[1]}$ Recent studies have reported an increase in the prevalence of $\mathrm{AD}$ worldwide, which has been attributed to changes in lifestyle, nutrition and other environmental factors. ${ }^{[6]}$

$\mathrm{AD}$ is characterised by pruritus, dry skin and a rash which may become lichenified with flexural involvement as the disease progresses. ${ }^{[7]}$ The chronic nature of $\mathrm{AD}$, characterised by flares, can have significant impact on patients and their families. ${ }^{[8]}$ In children, the most troublesome symptom is itching. ${ }^{[9]}$ The effect of night-time itching and scratching on sleep is often considerable. The sleep patterns in school-aged children with AD studied with home polysomnography were found to have frequent awakenings associated with scratching episodes, and reduced sleep efficiency compared with healthy controls. ${ }^{[10]}$ Children may lose up to 2 hours of sleep per night. ${ }^{[1]}$ Poor school performance characterised by daytime drowsiness and inability to focus has also been documented in affected children due to pruritus and daytime use of sedating oral antihistamines to alleviate the physical discomfort. ${ }^{[12]}$ Parents of young children with $\mathrm{AD}$ describe their children as being clingy, fearful and frustrated, as the presence of itchy, painful and weepy lesions may result in discomfort or pain on touch, which may impair parent-child bonding. ${ }^{[13]}$

Schoolchildren with $\mathrm{AD}$ tend to be more aware of their appearance compared with younger children, and may choose to abstain from play activities or to wear certain clothes in order to avoid embarrassment. ${ }^{[14]}$ This may affect relationships with peers and teachers. ${ }^{[15]}$ The demands of care can also negatively impact families, affecting spousal relationships and interfering with parents' care of other siblings. ${ }^{[15]}$ Lawson et al ${ }^{[14]}$ evaluated the burden of care among parents of children with $\mathrm{AD}$, and observed that $71 \%$ of parents felt psychological pressures, including guilt, exhaustion, frustration, resentment and helplessness, while $64 \%$ of parents admitted to having their sleep disturbed by the night-time itching and scratching of their child.

Health-related quality of life (HRQL) denotes the state of an individual's quality of life (QOL) as it pertains to health and disease and/or treatment. ${ }^{[16]}$ HRQL measurements are needed for comparison between alternate treatments, provision of information for evaluation of survival data, allocation of resources in healthcare, auditing of health services and as aids in management decisions. ${ }^{[17]}$ QOL can also be used to assess the burden of illness and the outcomes of related medical treatments. ${ }^{[8]}$ 
The Dermatology Life Quality Index (DLQI) is the most frequently used dermatology-specific QOL instrument in randomised clinical trials in dermatology. ${ }^{[18]}$ It has been modified for use in children aged $<5$ years as the Infant's Dermatitis Quality of Life Index (IDQOL) ${ }^{[9]}$ Similarly, the Children's Dermatology Life Quality Index (CDLQI) has been adapted for use in schoolchildren aged $5-16$ years. ${ }^{[18]}$ Akinboro et al ${ }^{[19]}$ validated the CDLQI in a study of children with tinea capitis in a rural community in Oshogbo, Nigeria, making it suitable for use in Nigeria.

The impact of $\mathrm{AD}$ on the QOL of affected children is well recognised in developed countries. ${ }^{[20,21]}$ However, these findings cannot simply be extrapolated to children in developing countries. Hence the aim of this study was to examine the impact of $\mathrm{AD}$ on QOL in Nigerian children, to identify relationships between patient variables, disease severity and QOL in AD. Information obtained from the patient point of view will improve the current understanding of the disease burden. This will promote better patient compliance and provide additional data for proper healthcare planning.

\section{Materials and methods}

This cross-sectional study was conducted between November 2012 and May 2013 in the dermatology clinic of the Lagos University Teaching Hospital, Idi-araba, Lagos State, Nigeria. The sample in this study was drawn from 228 children aged $\leq 16$ years who attended the clinic during the study period for the first time. The study population was calculated using the sample size formula for a finite population ${ }^{[22]}$ with a prevalence rate of $7 \%$, based on an ISAAC Study in Nigeria. ${ }^{[23]}$ Participants and their parents/guardians were provided with detailed information about the study and assured that confidentiality would be ensured. The inclusion criteria were a diagnosis of $\mathrm{AD}$, according to the UK Working Party's (UKWP) ${ }^{[24]}$ diagnostic criteria, the age range of the children (from newborn to 16 years) and oral and/or written informed consent. The exclusion criteria were inability to obtain parental consent/assent for adolescents, previous clinic attendance and the presence of any chronic non-dermatologic medical condition that may have had an additional impact on QOL. The participating children were divided into three age groups: $<5$ years, $5-10$ years and $11-16$ years.

\section{Case definition}

For the purpose of this study, the UK Working Party (UKWP) ${ }^{[24]}$ criteria for the diagnosis of $\mathrm{AD}$ were used to identify cases. These criteria have been validated in Nigeria by Odusote. ${ }^{[25]}$ A diagnosis of $\mathrm{AD}$ is made in the presence of a pruritic rash and three or more of the following features:

(i) a history of rash in the skin creases (fold of the elbow, behind the knees, front of the ankles and around the neck);

(ii) a personal or family history of asthma and hay fever;

(iii) history of generalised dry skin (xerosis);

(iv) onset before the age of 2 years; and

(v) visible flexural dermatitis.

\section{Data collection}

Demographic data of all individuals recruited for the study, including biodata and composite variables (father's and mother's occupations and levels of education) to assess the socioeconomic status of the patient, were recorded.

\section{QOL assessment}

QOL was assessed among all recruited subjects using the English or Yoruba versions of either the IDQOL for children aged $<5$ years, or the CDLQI for children aged 5 - 16 years. The QOL questionnaires were self-administered. The primary investigator explained to the caregiver or child how to complete the questionnaires prior to answering them. For children $<5$ years old, the IDQOL questionnaire was completed by caregivers. Children aged $5-16$ years answered the CDLQI questionnaires; the parents/guardians helped the younger children to understand the questionnaires, while the older children answered the questions themselves.

IDQOL index: ${ }^{[9]}$ The IDQOL was used for children $<5$ years and was completed by the parent or caregiver. The IDQOL consists of 10 questions that address symptoms and difficulties with mood, sleep (two questions), play, family activities, mealtimes, treatments, dressing and bathing over the last week. Each question has 4 options as answers, which are scored $0-3$ according to the severity of the symptoms, with 3 as the most severe.

CDLQI: ${ }^{[18]}$ The CDLQI was used to measure QOL in children aged 5 - 16 years. It comprises a 10-question questionnaire on symptoms of $\mathrm{AD}$, in subscales relating to symptoms and feelings (questions 1 and 2), leisure (questions 4, 5 and 6), school or holidays (question 7), personal relationships (questions 3 and 8), sleep (question 9) and treatment (question 10), within the last week. Each question of the CDLQI is answered by 'not at all,' 'only a little,' 'quite a lot,' or 'very much', and scored $0,1,2$ or 3 , respectively. The one exception to this scoring system is found in question 7 , where the possible answer 'very much' is replaced by 'prevented school', and the question is also scored $0-3$.

For both the IDQOL and CDLQI, each subject's total score was calculated by adding the scores of the 10 questions. The highest possible score is 30 , and the lowest 0 ; the higher the score, the more the QOL of the subject is considered impaired. Total QOL scores of $0-10,11-20$ and $>20$ represent mild, moderate and severe impairment, respectively. ${ }^{[26]}$

\section{Assessment of disease severity}

The objective SCORing of Atopic Dermatitis (obj-SCORAD) index ${ }^{[27]}$ was used to assess AD disease severity, where the higher the score, the more severe the skin condition. It consists of a combination of two items: topography, or extent of skin involvement (section A), and intensity of dermatitis (section B).

Individuals with $\mathrm{AD}$ were taken to a well-lit, quiet, private and warm room. After ensuring that parental consent/subject assent were still valid, these subjects were asked to undress to allow for close observation of the skin, and then examined by the primary investigator.

To assess disease extent/surface area (A), affected areas of skin were plotted on the Wallace rule of nines body chart ${ }^{[28]}$ section of the obj-SCORAD to estimate the total percentage area affected. Disease extent is graded from $0-100 \cdot{ }^{[27]}$ For disease intensity $(\mathrm{B})$, the primary investigator assessed six clinical signs - erythema, oedema/ induration, excoriation, lichenification, oozing/crusting and dryness (xerosis) - at a single representative site (the most affected). Each sign was graded from 0 to $3(0=$ absent; $3=$ severe $)$. Disease intensity was graded as $0-18 .{ }^{[27]} \mathrm{Obj}-\mathrm{SCORAD}$ is a weighted index, with greater emphasis placed on intensity (multiplying by a factor of 3.5), and less weight on the extent (multiplying by a factor of 0.2$){ }^{[27]}$ The highest possible score is 83 .

The obj-SCORAD score was calculated using the formula $(\mathrm{A} / 5+7 \mathrm{~B} / 2) \cdot{ }^{[27]}$ Total obj-SCORAD scores were classified as mild $(<15)$, moderate $(15-40)$ or severe $(>40)$, following the recommendation by Kunz et al. ${ }^{[27]}$ Disease severity was estimated by the same dermatologist using the obj-SCORAD index.

\section{Translation protocol}

Written permission was obtained from the owners of the IDQOL questionnaire for its translation and use in the study. Two forward translations into the Yoruba language were carried out by two independent bilingual native Yoruba translators, after which an agreement on a translation was reached. This consensus version was translated back 
into English by a third and a fourth independent bilingual translator. These two distinct translations were reviewed by the copyright holders. In addition, the graphical layout of the questionnaire was kept as close to the original English version as possible.

\section{Socioeconomic status}

Parents' socioeconomic status was classified into upper (I and II); middle (III) and lower (IV and V) groups using the method described by Oyedeji. ${ }^{[2]}$ This method of classification uses the parents' level of education and occupation to categorise the parents into socioeconomic groups I - V.

\section{Ethical clearance}

The study protocol was approved by the Health Research Ethics Committee of the Lagos University Teaching Hospital (LUTH) Lagos, Nigeria (ref. no. ADM/DCST/HREC/APP/1252). Privacy and confidentiality were ensured by avoiding the use of sensitive information and real names in the questionnaire for data collection.

\section{Statistical analysis}

Data were collected and stored on an electronic database. Statistical analysis was performed using SPSS (IBM Corp., USA) package for Windows (Microsoft, USA) version 20.0. Disease severity groups (mild, moderate, severe) were classified in function according to the obj-SCORAD ranges. ${ }^{[27]}$ Normally distributed quantitative variables were analysed using $t$-tests and analyses of variance (ANOVA). For skewed distribution, Mann-Whitney U-tests, Kruskal-Wallis tests and Spearman's rank correlations were used.

Specifically, total QOL (CDLQI and IDQOL) scores and items (questions) were compared between the sociodemographic groups. Correlation tests were carried out to determine associations between sociodemographic variables (age, gender and socioeconomic status) disease severity and total QOL scores. Further analysis was carried out to determine what variables were associated with severe QOL impairment, which was taken as a QOL score $>20$. QOL scores of individuals with $\mathrm{AD}$ (according to age, gender and $\mathrm{AD}$ severity groups) were compared ( $p<0.05$ was considered statistically significant).

\section{Results}

A total of 228 children were seen during the study period; of these, $47 \mathrm{AD}$ cases were identified using the UKWP diagnostic criteria, and included in the study. Of these, 25 were $<5$ years old, while 22 were aged between 5 and 16 years. Demographic information for the cohort is listed in Table 1.

\section{IDQOL index}

The median (IQR) IDQOL score was 6.0 (3.0 - 15.5; $n=25)$. Questions on itching/scratching, mood, time taken to get to sleep, treatment and dressing were the highest-scoring items (Table 2).

\section{CDLQI}

The median (IQR) CDLQI score was 9.5 (7.75 - 17.75; $n=22)$. The highest-scoring CDLQI items were questions on itching/scratching, embarrassment and play (Table 2).

Table 3 shows the QOL (IDQOL/CDLQI) scores of children with $\mathrm{AD}$ by sex. The median QOL score was higher among females than males. However, this difference was not statistically significant (Mann-Whitney $\mathrm{U}=2.070 ; p=0.150$ ).

Among children with AD, median QOL (IDQOL/CDLQI) scores increased with age, but this was not statistically significant (KruskalWallis $\chi^{2}=5.327 ; p=0.70$ ) (Table 4 ).

Table 5 shows that there was no significant difference in QOL (IDQOL/CDLQI) scores across the socioeconomic classes (KruskalWallis $\chi^{2}=0.133 ; p=0.936$ ).
Table 1. Sociodemographic characteristics of study population

$(N=47)$

\begin{tabular}{ll}
\hline Characteristic & $\boldsymbol{n}(\%)^{*}$ \\
\hline Age (years) & $25(53.2)$ \\
$<5$ & $18(38.3)$ \\
$5-10$ & $4(8.5)$ \\
$11-16$ & $4.71(3.6)$ \\
Age, mean (SD) & \\
Sex & $24(51.1)$ \\
Male & $23(48.9)$ \\
Female & \\
Parents' socioeconomic status & $26(55.3)$ \\
Upper & $11(23.4)$ \\
Middle & $10(21.3)$ \\
Lower & \\
QOL score (IDQOL/CDLQI) & $10.5(7.5)$ \\
Mean (SD) & $8.0(5.0-16.0)$ \\
Median (IQR) & \\
IDQOL = Infants' Dermatitis Quality of Life Index; CDLQI = Children's \\
Dermatology Life Quality Index; SD = standard deviation; IQR = interquartile range. \\
${ }^{*}$ Unless otherwise indicated.
\end{tabular}

Using Spearman's correlation, there was no significant correlation observed between QOL scores and age, gender and socioeconomic status. However, a significant correlation was observed between QOL scores and disease severity (obj-SCORAD) $\left(r_{s}=0.328 ; p=0.024\right)$. There was no significant correlation between disease severity (obj-SCORAD scores) and age, gender and socioeconomic status (Table 6).

\section{Discussion}

The study identified 47 children with AD who met the UKWP diagnostic criteria. Just over half (53.2\%) of the children identified were $<5$ years old, while the frequency was lowest among 11-16 years of age. This finding is in agreement with prevalence trends shown in other studies in Nigeria. ${ }^{[3-5]}$ Previous epidemiological findings have also shown that $\mathrm{AD}$ typically occurs most commonly among infants, and the prevalence decreases with increasing age. ${ }^{[1]}$

The index study revealed that AD significantly impacts on the QOL of affected children. The mean (SD) QOL (IDQOL/CDLQI) score for children with $\mathrm{AD}$ in this study was 10.5 (7.5), which was higher than the scores of 9.2 (7.8) and 7.7 (5.6) observed by Lewis-Jones and Findlay ${ }^{[18]}$ and Beattie and Lewis-Jones, ${ }^{[20]}$ respectively, among children with $\mathrm{AD}$ in paediatric dermatology clinics in the UK. However, the observed mean score was comparable to the 9.8 (4.5) observed among children with $\mathrm{AD}$ in Egypt. ${ }^{[30}$ The high mean QOL score observed in the index study may be attributed to the high proportion of individuals with moderate to severe disease, which was also the case in the Egyptian study; over $80 \%$ of subjects had moderate to severe disease in both studies. Lower mean QOL scores have been documented among children with $\mathrm{AD}$ recruited from general practice clinics, owing to a lower proportion of severe cases. ${ }^{[0,31]}$

The question on 'itching' was the highest-scoring question in both the IDQOL and CDLQI questionnaires. This corroborates reports on children with $\mathrm{AD}$ in numerous countries worldwide. ${ }^{[7,9,31,32]}$ Pruritus is the hallmark of $\mathrm{AD}$, reported in up to $91 \%^{[11]}$ of affected individuals. Previous reports have established a significant association between QOL impairment and pruritus in $\mathrm{AD}^{[10,11]}$ and may explain this trend.

Among children $>5$ years, the itching was severe enough to affect questions on 'mood', and 'time taken to get child to sleep'. Previous studies have reported that night-time itching in children with $\mathrm{AD}$ affects both the quality and quantity of patients' sleep. ${ }^{[33]}$ This may cause tiredness, irritability and problems with concentration and 
Table 2. IDQOL and CDLQI scores of children with AD

\begin{tabular}{|c|c|c|c|}
\hline IDQOL items & $\begin{array}{l}\text { Median (IQR) } \\
n=25\end{array}$ & CDLQI items & $\begin{array}{l}\text { Median (IQR) } \\
n=22\end{array}$ \\
\hline Itching/scratching & $2.00(1.00-3.00)$ & Itching/scratching & $3.00(2.75-3.00)$ \\
\hline Mood & $1.00(0.00-2.50)$ & Embarrassment & $2.00(1.00-3.00)$ \\
\hline Time to get to sleep & $1.00(0.00-2.00)$ & Friendships & $1.00(0.00-2.25)$ \\
\hline Sleep disturbance & $0.00(0.00-2.00)$ & Clothing & $0.00(0.00-1.00)$ \\
\hline Playing & $0.00(0.00-1.00)$ & Playing & $2.00(0.00-3.00)$ \\
\hline Family activities & $0.00(0.00-1.00)$ & Sporting activities & $0.00(0.00-1.25)$ \\
\hline Mealtimes & $0.00(0.00-1.00)$ & School & $1.00(0.00-2.00)$ \\
\hline Treatment & $1.00(0.00-2.00)$ & Teasing/bullying & $0.50(0.00-2.00)$ \\
\hline Dressing & $1.00(0.00-2.00)$ & Sleep & $1.00(0.00-2.25)$ \\
\hline Bath time & $0.00(0.00-1.50)$ & Treatment & $1.00(0.00-2.00)$ \\
\hline Total IDQOL score & $6.00(3.00-15.50)$ & Total CDLQI score & $9.50(7.75-17.75)$ \\
\hline
\end{tabular}

IDQOL = Infants' Dermatitis Quality of Life Index; CDLQI = Children's Dermatology Life Quality Index; AD = atopic dermatitis; IQR = interquartile range.

Table 3. QOL scores among children with AD by sex $(N=47)$

\begin{tabular}{lll}
\hline Sex & Frequency, $\boldsymbol{n}$ & $\begin{array}{l}\text { Median (IQR) } \\
\text { QOL score }\end{array}$ \\
\hline Female & 24 & $9.50(6.00-16.25)$ \\
Male & 23 & $7.00(3.50-14.00)$
\end{tabular}

$\mathrm{QOL}=$ quality of life; IQR $=$ interquartile range

Mann-Whitney $\mathrm{U}=2.070 ; p=0.150$.

Table 4. QOL scores among children with $\mathrm{AD}$ by age group $(N=47)$

\begin{tabular}{lll}
\hline Age (years) & Frequency, $\boldsymbol{n}$ & Median $(\mathrm{IQR})$ \\
\hline$<5$ & 10 & $6.00(3.00-15.00)$ \\
$5-10$ & 11 & $9.40(7.25-16.75)$ \\
$11-16$ & 26 & $12.00(8.00-17.75)$
\end{tabular}

$\mathrm{QOL}=$ quality of life; IQR $=$ interquartile range

Kruskal-Wallis $\chi^{2}=5.327 ; p=0.70$.

Table 5. QOL scores among children with AD by socioeconomic class $(N=47)$

\begin{tabular}{lll}
\hline $\begin{array}{l}\text { Socioeconomic } \\
\text { status }\end{array}$ & Frequency, $\boldsymbol{n}$ & Median $(\mathrm{IQR})$ QOL score \\
\hline Lower & 10 & $8.50(7.25-14.50)$ \\
Middle & 11 & $8.00(5.50-13.00)$ \\
Upper & 26 & $9.50(4.00-16.00)$ \\
QOL = quality of life; IQR $=$ interquartile range. \\
Kruskal-Wallis $\chi^{2}=0.133 ; p=0.936$.
\end{tabular}

Table 6. Spearman's correlation matrix between sociodemographic variables (age, gender and socioeconomic status), disease severity (obj-SCORAD) and QOL scores

\begin{tabular}{lll}
\hline Variable & $\boldsymbol{r}_{\boldsymbol{s}}$ & $\boldsymbol{p}$-value \\
\hline Age & -0.043 & 0.774 \\
Gender & 0.113 & 0.450 \\
Socioeconomic status & 0.279 & 0.058 \\
QOL & 0.328 & 0.024
\end{tabular}

Obj-SCORAD = Objective SCORing of Atopic Dermatitis score; $\mathrm{QOL}=$ quality of life.

$r_{s}=$ Spearman's correlation co-efficient. learning, resulting in poor performance at school. ${ }^{[7,31]}$ The questions on 'treatment' and 'problems with dressing' also scored highly in this study. This may be due to the frustration of parents with obtaining effective treatment and appropriate clothing for their children. AD is a chronic condition and runs a relapsing course. Morrone ${ }^{[34]}$ notes that in developing countries, over $90 \%$ of cutaneous conditions are treated by primary care providers with little or no dermatology training, resulting in high failure rates. In addition, the trend towards self-medication with potent topical steroid creams and topical herbal applications may further worsen the disease, and consequently patients' QOL. ${ }^{[35]}$ In our study, both of these situations were confirmed, as over $80 \%$ of subjects had been to a general practitioner or used steroid creams prior to recruitment.

In the group of older children evaluated using the CDLQI, 'feelings of embarrassment' and 'playing' were also affected. In South Korea, Kim et al. ${ }^{[32]}$ reported itching, sleep and feelings of embarrassment as the most highly rated problems among children with $\mathrm{AD}$ aged 5 - 16 years. A similar observation was made by Ben-Gashir et al. ${ }^{[31]}$ among children in the UK. In this study, children affected by $A D$ felt embarrassed/self-conscious about their skin problem, and this was severe enough to interfere with playtime and schooling. This corroborates reports in numerous studies among children with $\mathrm{AD}$ in developed countries. ${ }^{[8,31]}$ Stigmatisation of children with skin disease, especially $\mathrm{AD}$, is common, as reflexes that associate any skin disease with contagion are still prevalent. ${ }^{[36]}$ This may cause avoidance in peers, and in some instances, children may be excluded in the long term from school for fear that they will infect other children with a contagious disease.

The impact of age, gender, socioeconomic status and disease severity as determinants of QOL was also evaluated in the present study. Disease severity (the obj-SCORAD score) was the only factor associated with QOL impairment in the children. A significant positive correlation was observed between obj-SCORAD scores and QOL scores (that is, the greater the disease severity, the greater the QOL impairment). This compares with the results of studies among children with AD in Italy, ${ }^{[37]}$ Egypt $^{[30]}$ and the UK. ${ }^{[31]}$ Hassabel-Naby et al. ${ }^{[30]}$ in Egypt evaluated 100 school-aged children with $\mathrm{AD}$ recruited from a dermatology clinic, and observed significantly greater QOL impairment with increasing disease severity. By contrast, Van Valburg et al. ${ }^{[9]}$ in a study of preschool children with $\mathrm{AD}$ recruited from a general practice clinic, reported no significant association between QOL scores and obj-SCORAD scores, which was probably a result of using a proxy estimation of QOL and there being a larger proportion of individuals with mild disease. 
Few studies have utilised the obj-SCORAD index to evaluate the severity of $\mathrm{AD}$ among children in sub-Saharan Africa. The mean (SD) obj-SCORAD score in this study was 34.4 (17.2), which was comparable to the 27.9 (8.3) observed in Egypt. ${ }^{[30]}$ This is not surprising, as both studies were carried out in dermatology clinics. However, lower mean obj-SCORAD scores were reported in general practice clinics in the $\mathrm{UK}^{[38]}$ and the Netherlands. ${ }^{[9]}$ The higher proportion of individuals with moderate to severe disease in studies in dermatology clinics may be attributed to delays in presentation to the dermatologist, as there are few dermatologists in developing countries, with most within the tertiary hospitals. Therefore, in order to reduce the burden of care at the tertiary centres, there is a need for continued education of primary care providers on current treatment guidelines, to ensure effective management of $\mathrm{AD}$, thus reducing its impact on QOL.

\section{Limitations}

The study was carried out in a specialist dermatology clinic, which may introduce a selection bias for individuals with severe disease. As such, the observed correlation between QOL and disease severity should be interpreted with caution when extrapolated to general practice clinics/the general population. The possibility of information bias during data collection on QOL, as a proxy (parent/ caregiver) answered QOL questions for the children $<5$ years old, and also helped/guided the children between $5-10$ years to answer the questions. The ability to thoroughly assess school activity would have helped to better understand the impact of $\mathrm{AD}$ on school performance. In addition, a larger study involving both the public and private sectors would add more value to the research results.

\section{Conclusion}

Our study has revealed that $\mathrm{AD}$ significantly impairs the QOL of affected children, especially those with severe disease. Among children with $\mathrm{AD}$, greater disease severity is associated with greater impairment of QOL. It is therefore recommended that QOL measures are used in clinical practice, as this will offer additional data about QOL impairment in AD from the patient's point of view. This perspective is often missed by clinical evaluation alone. Such information from the patient's perspective will aid in healthcare decision-making, which will enhance comprehensive care and patient compliance.

Acknowledgements. We are extremely grateful to the children who participated in this study, their parents and the staff of the dermatology clinic, Lagos University Teaching Hospital, who were involved in their care, for the support given in publishing this manuscript.

Author contributions. All authors have read and agreed to the final version of this manuscript and have equally contributed to its content.

Funding. None.

Conflicts of interest. None.

1. Flohr C, Willams HC. Epidemiology of atopic dermatitis. In: Harper J, Oranje AP, Prose N, eds. Textbook of Pediatric Dermatology. 2nd ed. Malden: Blackwell Publishing, 2006:181-191.

2. Eichenfield LF, Hanifin JM, Beck LA, Lemanske RF Jr. Atopic dermatitis and asthma: Parallels in the evolution of treatment. Pediatrics 2003;111(3):608-616. https://doi.org/10.1542/peds.111.3.608

3. Emodi IJ, Ikefuna AN, Uchendu U. Skin diseases among children attending the outpatient clinic of the University of Nigeria teaching hospital, Enugu. Afr Health Sci 2010;10(4):362-366. https://www.ncbi.nlm.nih.gov/pmc/ articles/PMC3052811/pdf/AFHS1004-0362.pdf (accessed 19 April 2014).

4. Atraide D, Akpa MR, George IO. The pattern of skin disorders in a Nigerian tertiary hospital. J Public Health Epidemiol 2011;3(4):177-181. http:// www.academicjournals.org/journal/JPHE/article-abstract/D548B3F1325 (accessed 20 April 2013).
5. Onayemi O, Isezuo SA, Njoku CH. Prevalence of different skin conditions in an outpatients' setting in north-western Nigeria. Int J Dermatol 2005;44(1):7-11. https://doi.org/10.1111/j.1365-4632.2004.02298.x

6. Wollenberg A, Kraft S, Oppel T, Bieba T. Atopic dermatitis: Pathogenetic mechanisms. Clin Exp Dermatol 2000;25(7):530-534. https://doi.org/10.1046/ j.1365-2230.2000.00699.x

7. Friedmann PS, Ardern-Jones MR, Holden CA. Atopic dermatitis. In: Burns DA Breathnach SM, Cox NH, Griffiths CEM, eds. Rook's Textbook of Dermatology. 8th ed. Malden: Blackwell Publishing, 2010:1038-1071.

8. Kiebert G, Sorenson SV, Revicki DA. Atopic dermatitis is associated with a decrement in health-related quality of life. Int J Dermatol 2002;41(3):151-158. https://doi.org/10.1046/j.1365-4362.2002.01436.x

9. Van Valburg RW, Willemsen MG, Dirven-Meijer PC, Oranje AP, van der Wouden JC, Moed H. Quality of life measurement and its relationship to disease severity in children with atopic dermatitis in general practice. Acta Derm Venereol 2011;91(2):147-151. https://do.org/10.2340/00015555-3370

10. Stores G, Burrows A, Crawford C. Physiological sleep disturbance in children with atopic dermatitis: A case control study. Pediatr Dermatol 1998;15(4):264268. https://doi.org/10.1111/j.1525-1470.1998.tb01333.x

11. Yosipovitch G, Goon AT, Wee J. Itch characteristics in Chinese patients with atopic dermatitis using a new questionnaire for the assessment of pruritus. Int J Dermatol 2002;41(4):212-216. https://doi.org/10.1046/j.13654362.2002.01460.x

12. Reid P, Lewis-Jones MS. Sleep difficulties and their management in preschoolers with atopic eczema. Clin Exp Dermatol 1995;20(1):38-41. https://doi. org/10.1111/j.1365-2230.1995.tb01280.x

13. Chamlin SL, Frieden IJ, Williams ML, Chren MM. The effects of atopic dermatitis on young American children and their families. Paediatrics 2004;114(3):607-611. https://doi.org/10.1542/peds.2004-0374

14. Lawson V, Lewis-Jones MS, Finlay AY. The family impact of childhood atopic dermatitis: The dermatitis family impact questionnaire. Br J Dermatol 1998;138(1):107-113. https://doi.org/10.1046/j.1365-2133.1998.02034.x

15. Lapidus CS. Role of social factors in atopic dermatitis: The US perspective. J Am Acad Dermatol 2001(Suppl 1);45:S41-S43. https://doi.org/10.1067/ mjd.2001.117017

16. Halioua B, Beumont MG, Lunel F. Quality of life in dermatology. Int J Derm 2000;39(11):801-806. https://doi.org/10.1046/j.1365-4362.2000.00793.x

17. Finlay AY. Quality of life measurement in dermatology: A practical guide. Br J Dermatol 1997;136(3):305-314. https://doi.org/10.1046/j.13652133.1997.5541510.x

18. Lewis-Jones MS, Finlay AY. The Children's Dermatology Life Quality Index (CDQLI ( )): initial validation and practical use. Br J Dermatol 1995;132(6):942949. https://doi.org/10.1111/j.1365-2133.1995.tb16953.x

19. Akinboro AO, Olasode OA, Onayemi O, Mejiuni AD. The impact of tinea capitis on quality of life: A community-based cross-sectional study among Nigerian children. Clinical Med Insights: Dermatol 2013;6(1):9-17. https://doi. org/10.4137/CMD.S10781

20. Beattie PE, Lewis-Jones MS. A comparative study of impairment of quality of life in children with skin disease and children with other chronic childhood diseases. Br J Dermatol 2006;155(1):145-151. https://doi.org/10.1111/j.13652133.2006.07185.x

21. Gånemo A, Svensson Å, Lindberg M, Wahlgren C. Quality of life in Swedish children with eczema. Acta Derm Venereol 2007;87(4):345-349. https://doi. org/10.2340/00015555-0245

22. Araoye MA. Research Methodology with Statistics for Health and Social Sciences. 1st ed. Ilorin: Nathadex Publishers, 2004:117-119.

23. Williams H, Stewart A, von Mutius E, Cookson WO, Anderson RH, International Study of Asthma and Allergies in Childhood (ISAAC) Phase One and Three Study Groups. Is eczema really on the increase worldwide? J Allergy Clin Immunol 2008;121(4):947-954. https://doi.org/10.1016/j.jaci.2007.11.004

24. Williams HC, Burney PGJ, Archer CB, Shipley MJ. The UK Working Party's Diagnostic Criteria for Atopic Dermatitis. I. Derivation of a minimum set of discriminators for atopic dermatitis. Br J Dermatol 1994;131(3):383-397. https://doi.org/10.1111/j.1365-2133.1994.tb08530.x

25. Odusote OA. Atopic dermatitis in children attending the skin clinic at the Lagos University Teaching Hospital. Dissertation submitted to the National Postgraduate Medical College of Nigeria in partial fulfilment of the requirements for the fellowship of the College, November 2002.

26. Ricci G, Bendandi B, Bellini F, Patrizi A, Masi M. Atopic dermatitis: quality of life of young Italian children and their families and correlation with severity score. Pediatr Allergy Immunol 2007;18(3):245-249. https://doi.org/10.1111/ j.1399-3038.2006.00502.x

27. Kunz B, Oranje AP, Labreze L. Clinical validation and guidelines for the SCORAD index: Consensus report on the European Task force on Atopic Dermatitis. Dermatology 1997;195(1):10-19. https://doi.org/10.1159/000245677

28. Oranje A, Glazenburg EA, de Waard-van der Spek FB. Practical issues on interpretation of scoring atopic dermatitis: The SCORAD index, objective SCORAD and the three-item severity score. Br J Dermatol 2007;157(4):645648. https://doi.org/10.1111/j.1365-2133.2007.08112.x

29. Oyedeji GA. Socioeconomic and cultural background of hospitalised children in Ilesha. Nig J Paediatr 1985;12:111-117. http://www.njpaediatrics.com/1985/ v12n $4 / 2$ Socio $\% 20$ economic $\% 20$ and $\% 20$ Cultural $\% 20$ Background $\% 20$ of $\% 20$ Hospitalized\%20Children\%20in\%20Ilesha.pdf (accessed 16 April 2013). 
30. Hassab-el-Naby HMM, Mohamed YF, Ammar MA, Mostafa AM. Assessment of quality of life among school children with atopic dermatitis in a locality in Cairo. J Egypt Women Dermatol Soc 2011;8(1):7-10. https://doi. org/10.1097/01.EWX.0000392815.83337.7f

31. Ben-Gashir MA, Seed PT, Hay RJ. Quality of life and disease severity are correlated in children with atopic dermatitis. Br J Dermatol 2004;150(2):28490. https://doi.org/10.1111/j.1365-2133.2004.05776.x

32. Kim DH, Li K, Seo SJ. Quality of Life and Disease Severity Are Correlated in Patients with Atopic Dermatitis. J Korean Med Sci 2012;27(11):1327-32. https://doi.org/10.3346/jkms.2012.27.11.1327

33. Weber MB, Fontes Neto Pde T, Prati C, et al. Improvement of pruritus and quality of life of children with atopic dermatitis and their families after joining support groups. J Eur Acad Dermatol Venereol 2008;22(8):992-997. https://doi. org/10.1111/j.1468-3083.2008.02697.x

34. Morrone A. Poverty, health and development in dermatology. Int J Derm 2007;46(Suppl 2):S1-S9. https://doi.org/10.1111/j.1365-4632.2007.03540.x
35. Sylla RAD, Niane B. Artificial depigmentation practice of the skin in women of Dakar and analytical study of the cosmetic products used. Dakar Med 1994;39(2):223-226. https://www.ncbi.nlm.nih.gov/pubmed/8654183

36. Ring J. Management of patients with atopic eczema. In: Ring J. Atopic Dermatitis: Eczema. Berlin: Springer, 2016.

37. Monti F, Agostini F, Gobbi F, Neri E, Schianchi S, Arcangeli F. Quality of life measures in Italian children with atopic dermatitis and their families. Ital J Paediatr 2011;37:59. https://doi.org/10.1186/1824-7288-37-59

38. Beattie PE, Lewis-Jones MS. An audit of the impact of a consultation with a paediatric dermatology team on quality of life in infants with atopic eczema and their families: Further validation of the Infants' Dermatitis Quality of Life Index and Dermatitis Family Impact score. Br J Dermatol 2006;155(6):12491255. https://doi.org/10.1111/j.1365-2133.2006.07525.x

Accepted 23 April 2018. 